\title{
Analysis of Development of Birth Control Policy in China Under Economic Perspective
}

\author{
Xinyi Wang \\ Management School, University of Liverpool, Liverpool, L69 3BX, United Kingdom, \\ X.Wang237@student.liverpool.ac.uk
}

\begin{abstract}
The fertility restraint policy in China was officially announced in 1979 and still has continuous updates in recent years, intending to maintain continuity and stability of the demographic structure in China. This paper studies the economic effects of the birth control policy in China on the whole country and individuals (households). Many related papers are reviewed in this paper to support its view. The study shows: The economic effects caused by the policy mentioned in this paper are mainly focused on human capital, technological innovations, savings, labor income and welfare, which are separately discussed at the national level and then the individual level. For China, it will be beneficial to its human capital accumulation and technological innovations under the case that the one-child policy was initially issued. And for individuals(households), income inequality was also mitigated by such policy, while there are negative effects on human capital investment and welfare when the policy was relaxed. The decreasing number of intellectuals due to less attractive education investment is one of the adverse impacts. So, the necessity of the birth control policy in China is comprehensive in terms of its economic effects but it requires continuous and timely adjustments with other auxiliary policies issued to help its implementation.
\end{abstract}

Keywords: Birth control, economics, human capital, fertility, labor income

\section{INTRODUCTION}

A large population base and increasing population growth had been a key stressful problem in China [1], especially before the first issue of the one-child policy in 1979 when the whole country was burdened with the extreme low standard of living. With the gradual disappearance of demographic dividend, China was considering the adjustment of birth control policy and officially started universal two-child policy in 2015. Given the increasing concern about the aging population and demographic imbalances, the Chinese government recently updated its family planning regulations by allowing each couple to have up to three children in May 2021. Immediately, such updates brought a large stream of discussion on social media in China, especially among the young generation who holds different views. Questions about the economic effects of such transformation of birth control policy in China and the necessity to issue the latest fertility control policy were soon raised and being waited for answers based on scientific evidence.
This paper will first give a quick glimpse into the effects of the policies on population, forming a basic comprehension of its most direct consequences. Then, more details about economic influences will be discussed in multi-dimensional respect, such as at the national (society) level and individual (household) level, on the positive side and negative side. This paper will thus be able to provide a generally supported response by scholars' researches to the two questions raised above.

\section{INTRODUCTION OF CHINA BIRTH CONTROL POLICY DEVELOPMENT}

In the mid-1960s, the necessity of controlling the population in the global areas with a shortage of development was gradually accepted internationally. [2] The majority of scholars agreed that population boost had negative influences on economic development. Considering its own conditions, China issued a family planning programme, the one-child policy, in 1979 to alleviate pressure from overpopulation. The policy is usually considered to play an important role in the fall of fertility rate with an apparent decrease from 2.8 births per woman in 1979 to 1.5 by the mid 1990s. (shown as 
Figure.1) However, shortage of labor force, distorted demographics, aging problem and sex ratio disparity were thus followed in the next few decades in which way the demographic dividend-i.e. the economic growth brought by the falling birth rate- was going to disappear.
[3] Under such background, the two-child policy was officially issued in 2015 and designed to mitigate the problems mention above, especially the aging issue. Besides, the policy was as well expected to stimulate consumption related to children and offer more employment opportunities towards working-age people.

\section{Fertility Rate (births per woman) in China}

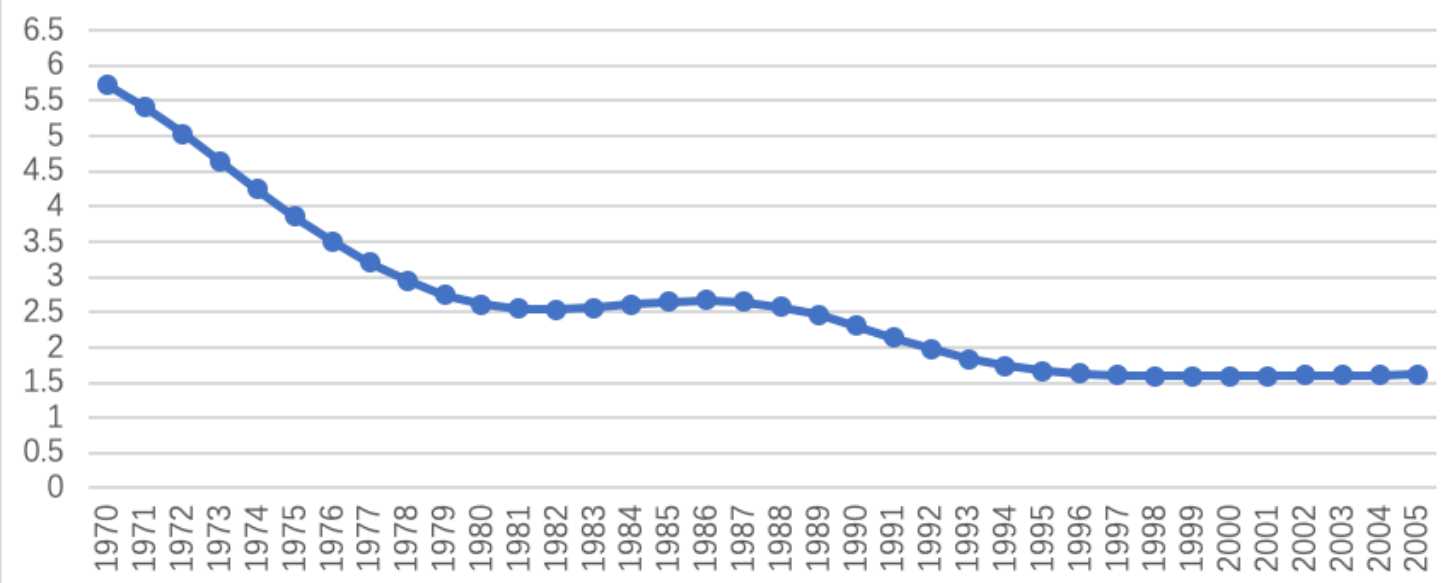

Figure 1. Fertility Rate (births per woman) in China

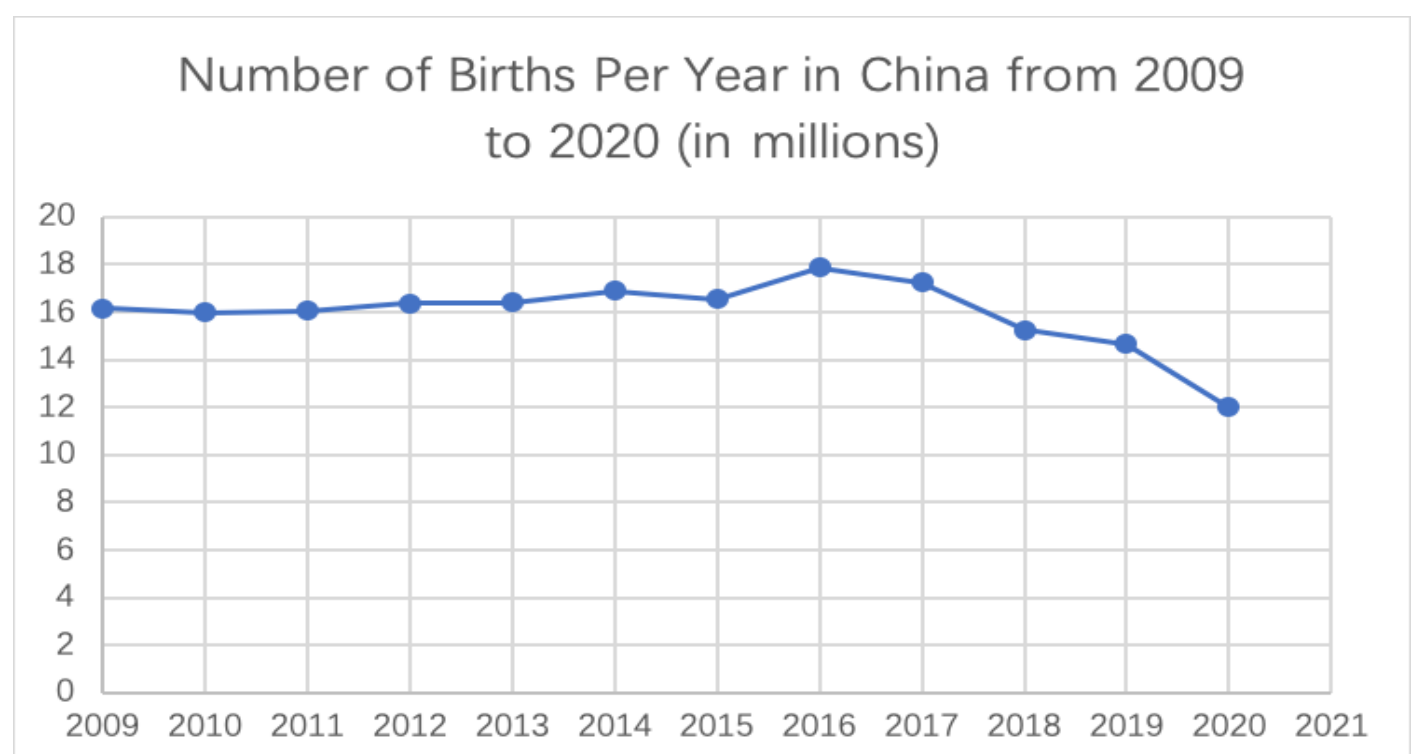

Figure.2 Number of Births Per Year in China from 2009 to 2020 (in millions)

Contrary to expectations, according to the latest 2020 demographic census, only 12 million children were born in 2020 extremely contrasted by the figure in 2016, 18 million births. (see in Figure.2) Such consequences might be caused by people's unwillingness to give birth and poor financial circumstances, and the lack of national supporting policies. [4] Recently in May 2021, China just announced a further easing of birth control policy, allowing each couple to have three children at most with specific exceptions on minorities as usual. Such policy reflects the urgency of optimizing the population structure in order to tackle already existing problems and potential crises in society. With the consideration of children's upbringing costs, family's daily living costs and so on, the public are currently speculating about the new policy.

\section{ECONOMIC EFFECTS OF BIRTH CONTROL}

It is undoubtful that any mistakes on population issue will have irreversible and long-term effects on economic 
society. It is usually considered by the government to transform demographic pressure into labor force advantages, supplying continuous mobility for the development of economic society. So, it is necessary to analyse the economic effects caused by the population problem in China and the corresponding policies expected to tackle the problem. Early after the announcement of the one-child policy, demand for economic development was first mitigated by the instantly slowed fertility rate since the public requirement at that time was simply at the survival level. And then the gross domestic product was boomed due to the controlled size of a growing population. During the period 2000 2020, ageing issue and labor supply shortage became the side-effects of the one-child policy and was gaining attention from not only the authority but also the whole society which will be discussed in detail in this sector in terms of economy.

\subsection{Birth Control Policy's Economic Effects on the Country}

The key point of birth control policy is to control new births in a country which is centred on the people in the society, and can be extended to the dimension of human capital. It is significantly related to the production where human capital can been seen as an input of production function in Solow model. According to Zhang and Wang, an assumption must be set first that the level of education in the entire society does not have a significant change where the education level refers to the ability of education's transforming inputs into human capital and to the level of the human capital. [1] Given the social education inputs conditioned on the constant social outputs, abundant human capital inputs on the underage will squeeze those on the adults who are of working age. With considerations of the assumption above, it takes more efforts for the underage youths to transform the inputs into human capital which has effect on production, resulting in negative influences on the accumulation of education human capital. Thus, birth control police, especially the one-child policy, is beneficial to the accumulation of human capital, and consequently contributing to the economic growth of China by effectively controlling the fertility rate and decreasing the population growth rate.

Also, from a Macroeconomic view, there is an unexpected and surprising relation between ageing and technological innovation effects on economic growth. [5] Though such effects have significant heterogeneity due to the variation of working experiences and education levels, the ageing people with rich backgrounds who own the high level of human capital are acceptable to new technologies and new ideas in general, thus having positive effects on technological innovation. Besides, because of the incomplete welfare policies, longer life expectancy and the traditional Chinese view of taking precautions, the proportion of the elders in a certain range or a certain period time will raise saving ratio as a mediation through which it then increases the economic development in China. [6]

However, the birth control policies in China do not always play a positive role in all respects, otherwise there would be no necessity to make continuous updates. The beneficial effects mentioned above are all restricted under some specific conditions and are unable to perform the same over time. More negative influences of the Chinese family planning programme will be discussed in the next sector, effects on individuals(households).

\subsection{Birth Control Policy's Economic Effects on Individuals (households)}

The implementation of a family planning programme in China is not only a strategy which is related to national demographic control and social sustainable development but also an opportunity, or sometimes a trigger to individuals(households). It is comprehensive that the people who follow the policy are individual members of the society, receiving the most direct consequences caused by their reproductive decisions. Naturally, with demographic dividends disappearing in the past few years, more negative effects of birth control in China on households are mentioned more frequently than before. However, it is still undeniable that the one-child policy in 1979 brought some positive, instrumental and relatively long-lasting influences on families in term of economic condition, family structure, etc.

One of the most mentioned directions by scholars is about the effects of labor income. It is the common case that unskilled couples tend to have more babies than skilled couples with fertility restrictions. The 1979 policy which allowed only one child for each couple successfully increased working hours taken by the unskilled people which should have been spent on taking care of more babies, bridging the income gap between unskilled and skilled parents. Besides, the potential labor supply was thus decreased. As a result, the policy in 1979 contributed to reducing income inequality and skill premium. [7] And then, considering a fall in household's human capital investment on child and a decrease in future intergenerational receipts of transfers, each household at that time largely increased family savings at that time. [8] 


\section{College share}

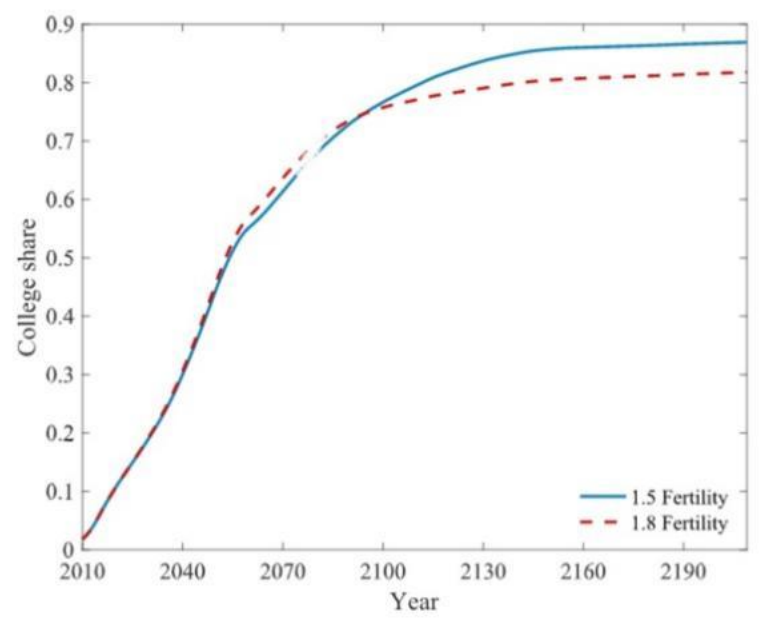

Figure.3 Transition paths for College Share for two Fertility Scenarios

Output per capita

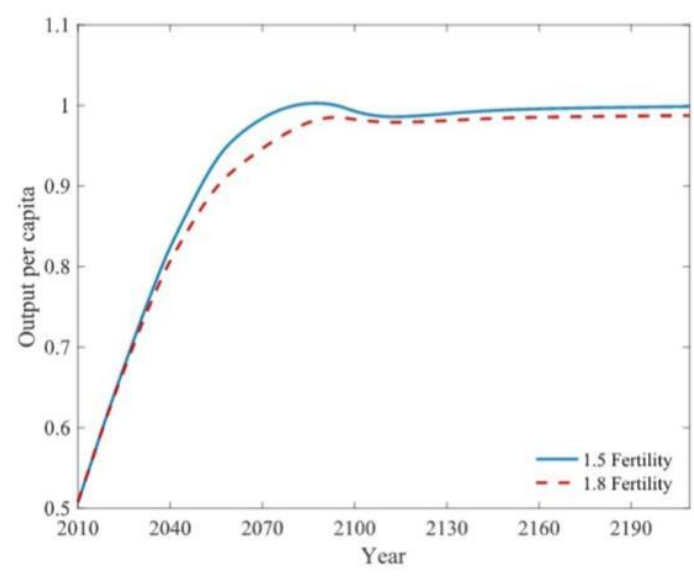

Figure.4 Transition paths for Output Per Capita for two Fertility Scenarios

However, as the first generation who had followed the first birth control policy was getting old later, crisis followed and was mainly extended effect due to distorting population structure. China consequently announced twice the relaxation of the birth control policy respectively in 2015 and 2021. However, the removal of the one-child policy, which makes higher fertility possible, might lead to unexpected results. Simply assuming a scenario of the higher fertility rate, 1.8, the existence of households without borrowing capacity on children's education, and the uncertainty of human capital investment for family with better financial performance makes human capital investment less attractive than physical capital investment. [9] (see college share in Figure.3) While high-quality human capital is perceived as guaranteed productivity and profitability. Such circumstance leads to a miss of improvement for family economic well-being. Though ignore the investment children's education first, the relaxation of birth control brings future generations less chance of capital accumulation due to diluted physical capital, thus shrunk labor income, lower level of individual outputs and even less welfare. [7] (see output per capita in Figure.4) Not to mention how dramatic the situation would be if the effects of the two mentioned above were combined with consideration of highly competitive children's education in reality.

\section{CONCLUSION}

Various papers related to the birth control policy in China and its economic effects on national level and individual(household) level are reviewed in this paper. Then, a basic analysis of fertility restraints has been accomplished in respects of human capital, savings, labor income, welfare, etc. The one-child policy plays a significant role in initial population strategy and has a positive effect on human capital accumulation and technology innovations for China and contributes to mitigating income disparity between households. However, the advantages of such policy faded away as time goes by with distorting demographic structure. New family planning programme was issued to relax the fertility restraints and was expected to boost fertility to alleviate problems such as ageing. However, it is worried by scholars that high fertility may bring some negative influences on households' human capital investment, welfare and so on. Both the country and individuals(households) are influenced in more dimensions by updates of fertility restraints. Besides, influences on individuals are more dynamic relative to those on the whole country, thus making it difficult to draw a general conclusion especially when policy updates happened more frequently these years. This paper focuses on aspects which are generally acknowledged by scholars and does not mention other effects that are still in the early phase of trial and full of controversy.

Theoretically, it is necessary to continuously update the birth control policy in China and it was early argued in 2006 that flexible adjustments of the policy were significant to maintain the continuity and stability of Chinese demographic policy. However, other related auxiliary policies should be noticed by the authority and need to be issued and implemented in time.[10] For example, policies of human resource development may ease the burden of households and raise general living standards. Moreover, medical security system needs to be improved in order to decrease the economic costs of diseases on individuals. In conclusion, it is not the end of the birth control policy in China and it still expects more improvements to be done in the future. 


\section{REFERENCES}

[1] Zhang, G., \& Wang, X. (2014) Dose Family Planning Policy Boost China's Economic Growth? Based on Educational Human Capital Theory, Journal of Zhongnan University of Economics and Lows, 204, 3-11.

[2] Wang, F., Yong, C., \& Gu, B. (2013). Population, policy, and politics: how will history judge china's one-child policy?. Population and Development Review, 38.

[3] Zeng, Y., \& Hesketh, T. (2016). The effects of china's universal two-child policy. The Lancet, 388(10054), 1930-1938.

[4] Goodkind, D. (2017). The Astonishing Population Averted by China's Birth Restrictions: Estimates, Nightmares, and Reprogrammed Ambitions. Demography, 54(4),1375-1400.

[5] Wang, J., \& Wang, S. (2017). Population aging, technological innovation and economic growthfrom the perspective of structural change of factor endowments. Journal of Xi'an Jiaotong University (Social Sciences), 37 (146), 27-38.

[6] Wu, Y..(2020). Research on the Regional Economic Growth Effect of China's Population Aging(Doctoral Dissertation,Northeast Normal University).https://kns.cnki.net/KCMS/detail/detail .aspx ?dbname $=$ CDFDLAST2021 $\&$ filename $=1021$ 509809.nh

[7] Liao,P. (2013). The one-child policy: a macroeconomic analysis. Journal of Development Economics, 101(Complete), 49-62.

[8] Choukhmane, T., Coeurdacier, N., \& Jin, K. (2013). The One-Child Policy and Household Savings. Meeting Papers. Society for Economic Dynamics.

[9] Bairoliya, N., \& Miller, R. (2021). Demographic transition, human capital and economic growth in china. Journal of Economic Dynamics and Control, $127,104117$.

[10] Hu, A. (2006). China's human development trend and long-term goals. China Academic Journal Electronic Publishing House, 9, 67-81. 